FROM THE EDITOR'S DESK

\title{
What Did the COVID Stress Test Reveal About How We Should Deliver Care in the USA?
}

\author{
Steven M. Asch, MD, MPH \\ J Gen Intern Med 36(11):3305-6 \\ DOI: $10.1007 / \mathrm{s} 11606-021-07150-4$ \\ (C) This is a U.S. government work and not under copyright protection in the \\ U.S.; foreign copyright protection may apply 2021
}

VA Palo Alto Center for Innovation to Implementation, Stanford School of Medicine, Stanford, USA

$\mathrm{C}$ onsider COVID's lessons for the future, and you will likely think of the public health miracle of rapid vaccine development, stumbles in public health messaging, and the concurrent pandemic of partisan misinformation. But COVID has lessons for personal health delivery too. Health services researchers used the COVID stress test to look for cracks in our delivery system. At JGIM, we have assembled a collection of our published COVID articles (https://link.springer.com/ collections/jhfbddgebc), and in this article, we review some of those and other attempts to draw COVID's lessons on the outcomes of access, value, and provider wellness in the United States.

Before the pandemic, researchers had long pointed out people of color and immigrants faced larger access barriers, and the pandemic widened this crack in our delivery system. Fear of contagion rapidly reduced the supply of in person visits, but not evenly. Blacks, Latinos, and immigrants, often at higher public health risk from essential jobs and crowded living conditions, contracted COVID more often, and were more likely to be hospitalized and die from it. ${ }^{1}$ For many patients, an astounding pivot to telemedicine bridged the access gap, but these traditionally excluded groups, most in need, got fewer video visits. ${ }^{2,3}$

In the Before Times, many lamented the disjunction between the value of care (defined here as the ratio of outcomes to cost) and how often it was delivered and how generously it was reimbursed. ${ }^{4}$ The pandemic highlighted this crack in our delivery system as well. Many procedures plummeted due to contagion concerns, and proceduralists' finances crashed. Yet procedure outcomes strangely remained similar, and a Danish study found that procedure starved heart disease patients' prognosis remained unchanged. ${ }^{5,6} \mathrm{High}$-value lifesaving intensive care skyrocketed, but the hospitals providing it lost money. ${ }^{7}$ The government and insurers responded with direct

Published online October 28, 2021 subsidies and increased reimbursement for telemedicine. Maybe the largest change was a massive increase in the ratio of social spending (e.g., unemployment insurance) to health care. While the pandemic pushed life expectancy downwards, higher social spending is strongly associated with better health outcomes in developed nations, and the US has long been at the bottom of the list. ${ }^{8}$

Provider wellness was already considered a crisis before the pandemic. Half of general internists reported burnout in national surveys; even a third of dermatologists were burned out! ${ }^{9}$ Few thought the strains of working during a pandemic would make that better, and it didn't. ${ }^{10}$ But many of us gained a new sense of mission and satisfaction amidst the hard work and family stressors, warming to reports of locked down citizens applauding our efforts from balconies.

The Japanese art of kintsugi highlights the cracks in damaged pottery with gold paint, honoring the traumatic history of the object while repairing it. Our health care system could undergo a similar post traumatic growth period and we all should weigh in. ${ }^{11}$ What gold paint would I apply to the cracks the pandemic revealed in our delivery system? The evidence supports continued efforts to ensure access to care for all Americans. The pandemic forcefully brought home how the health of all of us depends on the access to care of each of us. We should pay more for what works and less for what doesn't, and shift some of the enormous resources that health consumes to social spending. Perhaps most important to physicians and other health care workers, we should remember the meaning of our noble profession. We should strive to make it a more livable one.

Corresponding Author: Steven M. Asch, MD, MPH; VA Palo Alto Center for Innovation to Implementation, Stanford School of Medicine, Stanford, USA (e-mail: sasch@stanford.edu).

\section{REFERENCES}

1. Romano SD, Blackstock AJ, Taylor EV, El Burai Felix S, Adjei S, Singleton CM, Fuld J, Bruce BB, Boehmer TK. Trends in Racial and Ethnic Disparities in COVID-19 Hospitalizations, by Region - United States, March-December 2020. MMWR Morb Mortal Wkly Rep. 2021;70(15):560-565.

2. Garvin, L.A., Hu, J., Slightam, C. et al. Use of Video Telehealth Tablets to Increase Access for Veterans Experiencing Homelessness. J GEN INTERN MED 36, 2274-2282 (2021). 
3. Patel SY, Mehrotra A, Huskamp HA, Uscher-Pines L, Ganguli I, Barnett ML. Variation In Telemedicine Use And Outpatient Care During The COVID-19 Pandemic In The United States. Health Aff (Millwood). 2021;40(2):349-358.

4. Porter ME. A strategy for health care reform-toward a value-based system. N Engl J Med. 2009;361(2):109-12.

5. Butt JH, Fosbøl EL, Gerds TA, Andersson C, Kragholm K, BieringSørensen T, Andersen J, Phelps M, Andersen MP, Gislason G, TorpPedersen C, Køber L, Schou M. All-cause mortality and location of death in patients with established cardiovascular disease before, during, and after the COVID-19 lockdown: a Danish Nationwide Cohort Study. Eur Heart J. 2021;42(15):1516-1523.

6. Yong CM, Spinelli KJ, Chiu ST, Jones B, Penny B, Gummidipundi S, Beach S, Perino A, Turakhia M, Heidenreich P, Gluckman TJ. Cardiovascular procedural deferral and outcomes over COVID-19 pandemic phases: A multi-center study. Am Heart J. 2021;241:14-25.

7. Grimm, CA. Hospitals Reported That the COVID-19 Pandemic Has Significantly Strained Health Care Delivery: A U.S. Department of Health and Human Services Article. 2021 March, OEI-09-21-00140
8. Bradley EH, Elkins BR, Herrin J, Elbel B. Health and social services expenditures: associations with health outcomes. BMJ Qual Saf. 2011;20(10):826-31

9. Shanafelt TD, Boone S, Tan L, et al. Burnout and Satisfaction With WorkLife Balance Among US Physicians Relative to the General US Population. Arch Intern Med. 2012;172(18):1377-1385.

10. Forrest, C.B., Xu, H., Thomas, L.E. et al. Impact of the Early Phase of the COVID-19 Pandemic on US Healthcare Workers: Results from the HERO Registry. J Gen Intern Med 36, 1319-1326 (2021).

11. Olson K, Shanafelt T, Southwick S. Pandemic-Driven Posttraumatic Growth for Organizations and Individuals. JAMA. 2020;324(18):18291830.

Publisher's Note: Springer Nature remains neutral with regard to jurisdictional claims in published maps and institutional affiliations. 